\title{
Exploring new product portfolio management decisions: The role of managers' dispositional traits
}

\author{
Regina C. McNally ${ }^{\mathrm{a}, *}$, Serdar S. Durmusoglu ${ }^{\mathrm{b}, 1}$, Roger J. Calantone ${ }^{\mathrm{a}, 2}$, Nukhet Harmancioglu ${ }^{\mathrm{c}, 3}$ \\ ${ }^{a}$ Michigan State University, Eli Broad College of Business, Department of Marketing, N370 North, Business Complex, East Lansing, MI 48824, United States \\ ${ }^{\mathrm{b}}$ University of Dayton, School of Business Administration, 300 College Park, Dayton, OH 45469-2271, United States \\ ${ }^{c}$ Bilkent University, Faculty of Business Administration, Bilkent, Ankara, 06800 Turkey
}

Received 8 August 2006; received in revised form 20 July 2007; accepted 22 September 2007

Available online 31 October 2007

\begin{abstract}
Product strategy links to new product development (NPD) through new product portfolio management (NPPM). This dynamic decision process addresses the strategy implementation questions of identifying which new product ideas to pursue and their relative priorities. Despite the importance of NPPM in implementing product strategy, firms exhibit substantial performance-affecting differences. We investigate one potential source for such differences by examining the impact of managers' dispositional factors as a possible explanation. Using a case study research method, we examine differences in NPPM strategies and managers' revealed dispositional traits across three divisions of a single conglomerate firm operating in different business-to-business markets. Based on our analysis, we offer propositions relating managers' dispositions to NPPM strategy: analytic cognitive style is associated with balance, ambiguity tolerance is associated with strategic fit, and leadership style is associated with the relative weights applied to each dimension.
\end{abstract}

(C) 2007 Elsevier Inc. All rights reserved.

Keywords: New product portfolio management; Managers' dispositions; Case studies; Analytic cognitive style; Ambiguity tolerance; Leadership style

\section{Introduction}

Managing product development, where goods and service solutions that customers need and want are created, is so important in delivering customer value that Srivastava, Shervani, and Fahey (1999) categorize it as one of the three core business processes to which marketing contributes. Despite the importance of managing new product development (NPD), firms still struggle to achieve success in their NPD efforts (Griffin, 1997). Researchers investigating NPD best practices have delineated numerous processes to enhance success likelihood. One popular process is to implement an evaluation system where NPD acti-

\footnotetext{
* Corresponding author. Tel.: +1 517432 6378; fax: +1 5174321112 .

E-mail addresses: mcnally@bus.msu.edu (R.C.McNally),

durmuser@udayton.edu (S.S. Durmusoglu),rogercal@bus.msu.edu

(R.J. Calantone),nukheth@bilkent.edu.tr (N. Harmancioglu).

${ }^{1}$ Tel.: +1 937229 3540; fax: +1 9372293788 .

${ }^{2}$ Tel.: +1 517 3536381; fax: +1 5174321112 .

3 Tel.: +90 312290 1928; fax: +90 3122664958 .
}

vities are measured and evaluated on a pre-arranged schedule to assess if the development is proceeding to plan (Crawford, 1986). Evaluation decisions often are referred to as gates and encompass two decisions: first identifying a set of feasible projects by assessing individual projects against hurdles that all projects must clear, then prioritizing the multiple feasible projects to identify which will be developed (Cooper, Edgett, \& Kleinschmidt, 1997b).

Within such an evaluation process, the pre-development decisions are both critical and difficult. These pre-development evaluation decisions have been referred to as product portfolio selection (McDonough \& Spital, 2003) and as new product portfolio management (NPPM). NPPM is the dynamic decision process of evaluating, selecting, prioritizing, and allocating resources to product development projects (Cooper, Edgett, \& Kleinschmidt, 2001a). NPPM involves determining resource allocations to maximize the resulting program benefit given a set of alternatives that require common scarce resources (Baker, 1974). 
NPPM is critical because of the considerable budget and human resources firms commit and the opportunity costs incurred as projects move from screening to development (Cooper \& de Brentani, 1984). Empirical evidence reveals that product advantage and predevelopment task proficiency (i.e., project identification and selection) are correlated significantly with new product performance (Henard \& Szymanski, 2001). Product advantage is substantially affected by project selection decisions in that product features and benefits are defined prior to project selection. When firms improve their abilities to generate multiple new product ideas that are consistent with current product strategy and select the projects with the highest likelihood of success, new product performance should improve.

At the same time, NPPM is difficult because these critical decisions must be made with relatively little reliable information about customer demand, specific design requirements, and the total investment in both time and money that will be required (Cooper \& de Brentani, 1984). In addition, the ability of decision models to accurately select the best projects posthoc varies with both the criteria used and weights applied to the criteria (Baker \& Albaum, 1986). Perhaps for these reasons, managers often rate NPPM as the weakest NPD area and report that formal portfolio discussion and explicit decision criteria are lacking (Cooper et al., 2001a). As a result, managers suspect that their firms implement too many of the wrong types of projects.

Extant research examining NPPM focuses on identifying the criteria managers use to make such decisions. Researchers have reported the type and number of criteria managers use in NPPM (Baker \& Albaum, 1986; Carbonell-Foulquie, Munuera-Aleman, \& Rodriguez-Escudero, 2004; Cooper \& de Brentani, 1984; Rochford, 1991; Ronkainen, 1985) and have grouped the criteria into various evaluative dimensions (Cooper, Edgett, \& Kleinschmidt, 1997a; Tzokas, Hultink, \& Hart, 2004). An important conclusion from this research is that the criteria and dimensions used, as well as the formality of the evaluation processes, vary across firms. What has not yet been explored, however, is an examination of the source of this variation. How are the evaluative criteria and dimensions chosen? What drives the difference across firms? One potential factor influencing the choice of NPPM criteria that we examine here is that of manager dispositions. Dispositions (or personality traits) are stable characteristics or frames of reference associated with consistent ways of thinking, feeling, and behaving across situations (Chiu \& Francesco, 2003; Renn, Allen, Fedor, \& Davis, 2005).

Rather than organizational or environmental factors, personality characteristics largely explain management influence on innovations (Hoffman \& Hegarty, 1993). Much of the research investigating management influence on NPD focuses on managers' functional backgrounds (Gupta \& Govindarajan, 1984; Hart, Hultink, Tzokas, \& Commandeur, 2003; Hoffman \& Hegarty, 1993). However, past research hints that psychological forces influencing managerial interpretations have an impact on organizational change (Milliken \& Lant, 1991). Moreover, personality differences between marketing and R\&D personnel influence new product success through their impact on functional integration (Lucas \& Bush, 1988). While few research studies have explored the impact of dispositional factors on NPPM, these studies suggest that dispositional variables do play an important role (Mullins, Forlani, \& Walker, 1999).

We explore the role of managers' dispositions in NPPM by identifying several management characteristics affecting the use of NPPM evaluative dimensions. Given the lack of an established theory and scant empirical results in this area, our research is exploratory in nature and so we naturally employ a qualitative research case study approach. Specifically, we examine the NPD and NPPM processes being implemented at three different strategic business units (SBUs) operating in business-to-business markets of a single corporation. The corporation recently mandated the SBUs to grow via innovation rather than through mergers and acquisitions. Because these SBUs only recently began viewing new products as key to longterm survival, this is an ideal environment to study dispositions as they are implementing changes to improve the financial and market performance of their future product offerings. Moreover, potential variation due to such contextual variables as change impetus, industry, and ownership is minimized because the SBUs we examine operate in different business-to-business markets within the same general industry and are divisions of the same corporation.

This paper proceeds by first reviewing the extant literature regarding the evaluation dimensions used in NPPM decisions and the role of manager personality characteristics in strategy implementation and NPPM. Then, we describe the qualitative research methods we use to explore the potential relationships between managers' dispositions and NPPM evaluative dimension use. Subsequently, we summarize the NPPM strategies implemented in each of the three SBUs studied, as well as the managers' dispositions revealed in our interpretive analysis. Lastly, we offer propositions linking managers' dispositions to implemented NPPM strategies, and conclude with a discussion of the implications of this research.

\section{Literature review}

\subsection{NPPM evaluative dimensions}

Managers use different evaluation criteria or criteria weights at different evaluation points, or gates, in NPD processes. Research in this area suggests managers use three criteria types: product, market, and financial (Ronkainen, 1985). This research reveals that market criteria typically are important in early gates, product criteria are important in middle gates, and financial criteria are important in the later gates, although differences across firms are exhibited. Recent research elaborates further on these differences. Empirical research conducted with Spanish firms developing highly innovative products supports Ronkainen's (1985) results, adding strategic fit as an important evaluative criteria at the beginning of the NPD process (CarbonellFoulquie et al., 2004). Also, more criteria are used in early gates than in later gates, presumably to compensate for information inaccuracy in early NPD stages. Empirical research with Dutch and British firms reveals five evaluative dimensions: market- 
based, financial-based, product-based, process-based, and intuition-based (Tzokas et al., 2004). Unlike prior research, these researchers find that technical feasibility is assessed along with market-based criteria at concept ideation and development gates, while financial-based criteria are important at the business analysis gate to evaluate promising concepts.

Other researchers, particularly Cooper and his colleagues, explore in more detail the decision criteria used in the early gates, associated with choosing product ideas to develop. Cooper and de Brentani (1984) identify 86 screening criteria classified into eleven factors, four of which dominate: financial potential, corporate synergy, technological synergy, and product differential advantage. Rochford (1991) identifies a staged screening process, consisting of two steps. The first involves a lower-cost, coarser screen that examines only two criteria: consistency with firm objectives and feasibility. The reduced number of project ideas is submitted then to a more detailed screen in which multiple criteria relating to market, product, synergy, finances, and intuition are evaluated.

Cooper et al. (1997a) conclude that managers use three broad dimensions to evaluate the firms' portfolio of new product projects: value maximization, balance, and strategic direction. In the evaluative dimension of value maximization, managers evaluate NPD projects based on the financial returns they are likely to generate, such as long-term profitability or return on investment. This dimension is crucial as it distinguishes highperforming firms in the area of NPD from low-performing firms: the ability to load new product project portfolios with high-value projects is the NPPM dimension most strongly correlated to performance (Cooper, Edgett, \& Kleinschmidt, 2004b). Thus, it is most often used to evaluate new product projects (Cooper et al., 2001a).

In the evaluative dimension of balance, managers evaluate projects based on the extent to which they ensure that the mix of NPD projects is proportional across multiple concerns, such as project completion date, technical risk, return on investment, and project innovativeness (i.e., incremental vs. radical). Ensuring that the new projects to be implemented align with available resources also is a factor in balance. Balance, too, is a critical NPPM dimension as it is the second most strongly correlated practice with superior NPD performance (Cooper et al., 2004b).

Lastly, in the evaluative dimension of strategic direction, managers assess projects in terms of the extent to which they reflect firm strategy. Managers usually perceive that their new product project portfolios generally are aligned with their firms' strategic objectives (Cooper et al., 2004b), which is important because this dimension also correlates strongly with NPD performance (Adams-Bigelow, Kleinschmidt, Kuczmarski, Notargiacomo, \& Peters, 2006). However, managers believe their NPPM processes are not effective in accessing previously unserved markets, nor do these processes enable them to enter new product categories, areas, or product types (Cooper, Edgett, \& Kleinschmidt, 2004a). Furthermore, all firms are not equally effective in implementing this dimension, as project alignment with firm strategy is a strong discriminator between highperforming and low-performing firms.
While these dimensions are commonly used, the weight or emphasis given to each varies considerably across firms (Cooper et al., 1997b; Ronkainen, 1985). Over-emphasizing one dimension, such as evaluating only financial returns, is linked with poorer performance (Cooper, Edgett, \& Kleinschmidt, 1999).

Senior managers in high-performing firms consistently and significantly view NPPM as much more important than do senior managers in low-performing firms (Cooper et al., 2001a). Other senior manager practices that are important to successful NPPM include providing strong support, empowerment, and authority to NPD teams; understanding the firm's NPD process; involvement in the design of the NPD process; exhibiting a strong commitment to NPD; leaving day-to-day activities to the NPD teams (not micro-managing); and involvement in the gate and spending decisions (Cooper et al., 2004a; Griffin, 1997; Poolton \& Barclay, 1998). While prior research has been valuable in identifying practices that lead to NPD and NPPM success, the role of manager dispositions in the implementation of these practices has received little attention. Next we turn to a discussion of dispositional traits to explicate why this subject merits attention.

\subsection{Managers' dispositions and NPPM}

Successful strategy implementation, including organic growth strategy implementation via NPPM, depends in part on manager characteristics like functional expertise and personal dispositions (Gupta \& Govindarajan, 1984). Empirical research has explored the impact of functional expertise on strategy implementation in general and NPD implementation in particular. For example, greater expertise in marketing and sales is associated with more effective implementation of a growth strategy (Gupta \& Govindarajan, 1984). Further, top management influence on innovations is explained largely by functional expertise rather than organizational or environmental factors, such as industry, firm size, or firm structure (Hoffman \& Hegarty, 1993). Specifically, expertise in general management, marketing, production, $\mathrm{R} \& \mathrm{D}$, and finance is associated with extent of influence on such product/market innovation decisions as developing new products and targeting new markets and segments. In NPPM, functional expertise also appears to be associated with screening criteria use, as managers from marketing and sales use more market acceptance and product performance criteria than do R\&D managers (Hart et al., 2003).

The research exploring the impact of dispositional factors on NPPM has examined risk propensity. Risk propensity, defined as an individual's current tendency to take or avoid risks, can change over time (Lewin \& Weber, 1969) and is influenced by prior decision outcomes (Sitkin \& Weingart, 1995). Performance below acceptable levels is associated with reduced risk taking (Singh, 1986). In an NPPM experiment examining the effect of contextual variables on risky project selection, Mullins et al. (1999) find that risk propensity correlates significantly with project choice.

Other evidence also suggests that personality variables may play a role in NPPM. For example, a meta-analysis indicates that 
new product performance perceptions differ from objective performance measures and across managerial levels (Henard \& Szymanski, 2001). In addition, managers often misinterpret the factors that are important to NPD success, biased by their specific areas of interest and expertise. In the chemical industry, managers tend to over-rate the importance of such technical activities as product development, lab tests, and preliminary technical assessments while under-rating the importance of such business and marketing tasks as pre-commercialization business analysis, test markets, and marketing research (Kleinschmidt \& Cooper, 1995). However, a broad range of studies provides strong support for pre-development and marketing task proficiencies as being among the dominant drivers of NPD success (Henard \& Szymanski, 2001; Montoya-Weiss \& Calantone, 1994). Given that manager dispositions appear to play a role in NPPM decisions, we next briefly review the personality research.

\subsection{Dispositional traits}

The study of personality strives to divide the human mind into stable areas of function (Mayer, 1995, 1998). While various personality divisions have been proposed, the more fully developed approaches to personality structure are distinguished by their attempts to organize traits (Mayer, 2003), where trait refers to a measurable dimension of behavior (Nunnally, 1978). An influential approach is that of the Big Five factor structure, a broad conceptualization of personality traits resulting from factor analyses of personality adjectives classified as stable traits (Cattell, 1943, 1945; Goldberg, 1990). Research in this area provides strong evidence that any personality trait adjective can be viewed as a combination of the following five major factors: surgency (or extraversion vs. introversion), agreeableness, conscientiousness (or dependability), emotional stability (vs. neuroticism or emotional adjustment), and openness to experience (or intellect) (Goldberg, 1990).

Despite the Big Five structure, the taxonomy of personality traits is still an emerging research area. Currently, literature proceeds in two major distinct streams. In the first, scholars use the Big Five traits, employing all five or choosing only traits that are theorized as relevant for the study context. For example, Thoresen, Bradley, Bliese, and Thoresen (2004) test the validity of all Big Five personality traits in predicting pharmaceutical sales representatives' overall sales performance, finding that only conscientiousness and extraversion positively affect performance. Alternatively, Caldwell, Herold, and Fedor (2004) select only the trait of mastery in examining the relationships between organizational change and perceived changes in fit, finding that the relationships are best understood as interactions between change process characteristics, the extent of change, and individual differences.

In the other stream, scholars attempt to identify higher order constructs in hopes of achieving a breakdown of each of the Big Five into logical subgroups. For example, a meta-analysis indicates that measures of the four commonly studied traits of self-esteem, neuroticism, locus of control, and generalized selfefficacy are strongly related, perhaps indicating a higher order trait (Judge, Erez Thoresen, \& Bono, 2002). DeYoung (2006) demonstrates that neuroticism, agreeableness, and conscientiousness form one factor, whereas extraversion and openness/ intellect form another. In research investigating coping with change and managers' job performance, seven personality traits are reduced into two second order factors (Judge, Thoresen, Pucik, \& Welbourne, 1999). Both the specific traits and the second order factors exhibit significant associations with the outcome variables. In particular, the strongest correlation is between ambiguity tolerance and an independent assessment of a manager's coping with organizational change. The risk tolerance factor (comprised of openness to experience, ambiguity tolerance, and risk aversion) is positively related to managers' ability to cope with change and their organizational commitment.

To conclude, there is considerable research demonstrating that NPPM processes and decision criteria vary across firms, and that such differences affect new product performance. Research investigating the source of across-firm differences has focused more on managerial functional expertise and organizational and environmental variables, with little research investigating the role of managerial dispositions as a possible source of variation. Personality research suggests that dispositional traits are not invoked universally across all contexts; the operational traits are relevant to the context. Yet, no theory exists in NPPM research explicating the specific dispositional traits managers employ. Our exploratory research investigates this opening. Next, we describe our research method.

\section{Method}

The purpose of our research is to examine NPD and NPPM processes being implemented at three different SBUs operating in business-to-business markets of a single corporation. One year prior to the study, the corporation mandated that every SBU grow via innovation rather than through mergers and acquisitions. The mandate forced the SBU managers to implement NPPM processes to improve the financial and market performance of their future product offerings. Because the SBUs operate in different business-to-business markets within the same industry and are divisions of the same corporation, potential variation due to contextual variables such as industry, ownership, and change impetus is minimized. As a result, much of the variation in NPPM implementations results from differences across managers rather than from organizational and environmental causes.

To explore how managers' dispositions influence NPPM processes, we use a qualitative research case study method, which is advantageous when exploring a phenomenon where theoretical explanations are lacking (Eisenhardt, 1989). The type of case study method we use here is collective (Stake, 1995), reflected in the multiple managers and multiple SBUs participating in the case study. Case selection is important in case study research, not only because case variations allow for cross-case comparisons to identify the limits of the theory being developed (Yin, 1994), but also because data inaccessibility due to lack of cooperation from the case informants limits learning potential (Stake, 1995). 
Table 1

Informant characteristics and their implications

\begin{tabular}{|c|c|c|c|c|c|c|}
\hline SBU & Informant & Title & $\begin{array}{l}\text { Firm tenure } \\
\text { (year) }\end{array}$ & $\begin{array}{l}\text { NPD } \\
\text { experience }\end{array}$ & Other experience & Tenure and experience implications \\
\hline \multirow[t]{2}{*}{ SBU1 } & 1 & $\begin{array}{l}\text { VP of Marketing and } \\
\text { Product Development }\end{array}$ & 1 & Extensive & $\begin{array}{l}\text { Same industry, but former firm targeted } \\
\text { consumers with premium-priced products }\end{array}$ & $\begin{array}{l}\text { Expects customer involvement } \\
\text { in product development }\end{array}$ \\
\hline & 2 & $\begin{array}{l}\text { Sr. Director of Product } \\
\text { Development and Engineering }\end{array}$ & 6 & Extensive & $\begin{array}{l}4 \text { years prior with the holding company, } \\
\text { prior } 6 \text { years with a manufacturing firm. }\end{array}$ & $\begin{array}{l}\text { Strong informal networks; } \\
\text { knows firm culture very well }\end{array}$ \\
\hline \multirow[t]{3}{*}{ SBU2 } & 1 & $\begin{array}{l}\text { Director of Mfg. Services and } \\
\text { Product Management }\end{array}$ & $31 / 2$ & Moderate & $\begin{array}{l}\text { Plant manager for several years prior to } \\
\text { NPD, prior career in auto industry }\end{array}$ & Adversarial management style \\
\hline & 2 & Program Manager & 4 & Extensive & $\begin{array}{l}\text { Three different medical device companies } \\
\text { for } 5 \text { years each. Extensive experience } \\
\text { with project management software }\end{array}$ & $\begin{array}{l}\text { Viewed as project management } \\
\text { software expert }\end{array}$ \\
\hline & 3 & Sr. Product Manager & 9 & Moderate & Prior experience as a designer & $\begin{array}{l}\text { Extensive experience in } \\
\text { functions emphasizing creativity }\end{array}$ \\
\hline \multirow[t]{2}{*}{ SBU3 } & 1 & Sr. VP of Marketing & $21 / 2$ & Moderate & $\begin{array}{l}\text { Several years prior at a start-up electronic } \\
\text { commerce firm in same industry, } \\
\text { same industry for } 25 \text { years }\end{array}$ & $\begin{array}{l}\text { Highly knowledgeable of industry, } \\
\text { including technology and customers }\end{array}$ \\
\hline & 2 & $\begin{array}{l}\text { Sr. VP of Technology } \\
\text { and Purchasing }\end{array}$ & 12 & Extensive & $\begin{array}{l}\text { Entire career in same industry, } \\
\text { previously at a competitor }\end{array}$ & $\begin{array}{l}\text { Highly knowledgeable of } \\
\text { technology used in industry }\end{array}$ \\
\hline
\end{tabular}

To maximize the differences between cases for cross-case comparison, we explored NPD and NPPM implementation at SBUs that compete in different business-to-business markets in the U.S. within the overall industry category of building materials. In our sample, SBU1 sells to both construction companies and building material retailers, while SBU2 sells only to construction companies, and SBU3 sells primarily to building material retailers.

We employed two mechanisms to ensure data accessibility. First, we solicited approval from the corporation's top management team to conduct this research. By doing so, the corporation executives were able to identify four SBUs with managers who were potentially willing to participate, and were able to communicate to the SBU managers the importance of our research to the corporation. Second, we asked two managers at each SBU to complete a survey to identify the SBU's initial response to the corporate strategy change initiative. While the primary purpose of the survey was to provide additional data, the surveys also allowed us to assess willingness to participate in this research. Due to lack of response to the survey request, a fourth SBU was dropped from consideration for participation in the case study.

We employed data triangulation, which is the collection of multiple sources of data, to enhance the quality of our research (Stake, 1995; Yin, 1994). As identified above, we collected survey responses from at least two different managers at each participating SBU prior to the site visits. The survey items are based on the NPD literature (Cooper, 1993) and ask respondents to assess the SBU's strengths and weaknesses regarding NPD practices and metrics. The items address the specific areas of: NPD process monitoring; metrics in R\&D, NPD, and launch; formal business case development to justify resources for R\&D, new marketing efforts, and new product, process, and service development; sources of innovations; and performance measurement system effects. Respondents were chosen by SBU executives based on our instructions that respondents should be senior managers knowledgeable about their SBU's innovation strategy and implementation. Seven surveys were returned prior to the site visits, three from SBU3 and two each from the remaining SBUs.

Additional data were collected during the site visits, including NPD process documentation, SBU organizational structure charts, our direct observations, and manager interviews that were subsequently transcribed. To capture various perspectives within each SBU, we asked that managers participating in the interviews represent the different functional areas of $R \& D$ and marketing. Job titles and other characteristics of the seven informants are listed in Table 1.

The interview method we use is that of the 'long interview', which is designed to maximize the value of the informants' time through the use of an open-ended questionnaire (McCracken, 1988). The questions in the interview protocol were based on prior literature (Cooper et al., 2001b; Crawford, 1980), and served as the standard protocol to guide all of our field interviews. The open-ended questions included in the semi-structured interview protocol are listed in Table 2. The interviews

Table 2

Interview protocol

1) Do you set a strategic agenda for NPD programs? If so, how is it set? What are the financial, market, and product portfolio goals? What metrics are used?

2) Do you guide the cross-functional teams in their NPD activities based on a strategic agenda? Are goals also set for individual development projects?

3) How do you communicate these goals to the development teams? What are the items, steps, or routines followed while communicating goals to the NPD teams?

4) How do you make sure that the goals are communicated effectively and that the development processes are proceeding in the right direction? What, if any, metrics are used to monitor and control NPD projects?

5) Can you give an example where you guided the cross-functional teams in their NPD activities based on a strategic agenda for an individual project?

6) In general, what are the strengths and weaknesses of your firm in strategic agenda setting?

7) In general, what are the strengths and weaknesses of your firm's NPD process? 
typically lasted about one and a half hours and were audio recorded, except for the senior vice president (VP) of marketing at SBU3 who requested otherwise. We further enhanced the quality of our data collection by employing investigator triangulation, where at least two of the researchers were present in every interview (Stake, 1995). Investigator triangulation serves to enhance precision in findings, while the different insights add to the richness of the data (Eisenhardt, 1989). Investigator triangulation is especially important for data quality in the unrecorded interview, where three investigators were present.

We employed detailed within-case write-ups and cross-case pattern searches to analyze the data (Eisenhardt, 1989). The within-case write-ups were prepared in a two-step process. First, each investigator summarized the information from all informants at a single SBU. Then, one investigator integrated the individual within-case write-ups from each SBU into a combined within-case write-up. The investigators finalized the within-case write-up through discussion of gaps and agreement on the information. Remaining gaps and conflicts were resolved by further review of the transcripts and consultation with the SBU managers. Finally, we used member checks to ensure our comprehension of the situations is correct. The informants reviewed summaries of the within-case write-ups for their SBUs, which then were modified based on informants' comments.

To identify cross-case patterns, we used the matrix data display methods of Miles and Huberman (1994). First, we reviewed the data for each SBU to identify the extent to which they make use of each of the three NPPM evaluative dimensions of financial returns, balance, and strategic fit, as well as the weight they ascribe to each dimension. We tabulated our categorizations for each SBU into a single meta-matrix and observed that the SBUs vary across dimensions and weight. Similarly, we reviewed the data for each manager to identify the revealed dispositional characteristics. To avoid inaccurate reporting due to positive self-presentation bias, we interpreted informants' dispositions from the data rather than asking them directly about their dispositions. The research case study method is especially appropriate here because the relationships between dispositions and NPPM evaluative dimension use fall in the class of situations "where respondents cannot verbalize the underlying causes of behavior reliably" (Bonoma, 1985: 202). Given the lack of theory in this area, we allowed the data to reveal the manager dispositions that are relevant in NPPM. We tabulated our categorizations for each manager into a single meta-matrix, observing that the managers vary across dispositions. Finally, we created predictor-outcome matrices for each of the four NPPM variables (evaluative dimensions and the dimension weights) and the dispositional traits to identify patterns. The resulting matrices are discussed next.

\section{NPPM implementations}

The three SBUs we studied implement NPPM differently, as exhibited by the specific form each dimension takes at the SBUs and the relative importance they place on each of the three evaluative dimensions. Table 3 summarizes how the dimensions are implemented at each SBU, which we elaborate below. Our within-case write-ups revealed dominant decision-makers in two of the three SBUs, where dominance is the tendency to lead decision-making by directing others, influencing others, and making group decisions (Callaway, Marriott, \& Esser, 1985). We also briefly describe the NPPM process at each SBU to identify which informants dominate the various NPPM process steps.

\subsection{NPPM at $S B U 1$}

According to the within-case write-up summary, SBU1 is successfully positioned in its industry, with dominant market share and a reputation for quality. However, the firm is beginning to see competition at the low-price end of the market from Asian firms. Prior to the corporate innovation mandate, this SBU engaged in line extensions rather than radical innovation. To compete in this changing market and to comply with the corporate innovation mandate, SBU1 hired the vice president (VP) of marketing and product development (informant 1) with the explicit purpose of initiating a long-term NPD program. Informant 1 and the other executive managers review project proposals and prioritize the opportunities. Informant 1 dominates the process by persuading other executives to approve products aligned with the product strategy. SBU1 has implemented a new NPD and NPPM process they identified as 'design to market' with the strategy of competing through product differentiation rather than through low-price. The surveys and interviews reveal that new product ideas now are sourced indirectly from customers all along the supply chain by interpreting customers' unstated needs for products that are reliable and easy to install. As informant 1 describes, "We are going to create what they don't know they want yet."

Table 3

Use of NPPM evaluative dimensions at each SBU

\begin{tabular}{|c|c|c|c|c|}
\hline SBU & Financial returns & Balance & Strategic fit & Dimension weight \\
\hline SBU1 & Develop higher price-point products & $\begin{array}{l}\text { Product roadmaps balance product } \\
\text { innovativeness and release dates }\end{array}$ & $\begin{array}{l}\text { Identify latent customer needs for } \\
\text { product differentiation }\end{array}$ & Equal across dimensions \\
\hline SBU2 & $\begin{array}{l}\text { Short payback period, } \\
\text { sales likelihood, ROI }\end{array}$ & $\begin{array}{l}\text { Struggle to choose projects that } \\
\text { fit all the constraints }\end{array}$ & $\begin{array}{l}\text { Priorities combine customer input, sales } \\
\text { information, and resource constraints without } \\
\text { consideration of service differentiation strategy }\end{array}$ & Financial returns heaviest \\
\hline SBU3 & $\begin{array}{l}\text { Emphasize projects with high } \\
\text { likelihood of retailer adoption }\end{array}$ & $\begin{array}{l}\text { Evaluate technical feasibility } \\
\text { of projects }\end{array}$ & $\begin{array}{l}\text { Only develop premium brands to support } \\
\text { brand equity }\end{array}$ & $\begin{array}{l}\text { Financial returns heaviest } \\
\text { with other dimensions } \\
\text { acting as evaluation hurdles }\end{array}$ \\
\hline
\end{tabular}


The product differentiation strategy fits with their firm reputation of providing high-quality products, while at the same time allowing them to price their products at much higher price points. The higher price points support the financial return requirements the senior managers expect from NPPM. Informant 1 elaborates:

All of us [the executive committee] are making sure that this project achieves what we said it would in profitability, sales, margin, [and] production.

Finally, SBU1 now develops product roadmaps. The fiveyear product planning horizon includes new product platforms that are highly innovative for this firm, as well as a series of derivative products for each platform that provides enhancements to platform products. The product roadmap identifies what products will be released, when they will be released, and who will be working on the projects. As informant 1 describes:

Coming out of phase 2, we will have identified what that product road is for each team, which is recommended by the product team and reviewed and approved by the [executive] committee and sent back to the product team, so they know for a 3-5 year horizon what their projects are and what they will be working on and why.

The portfolio of new platforms and enhancements is how SBU1 will maintain NPPM balance. Therefore, SBU1 equally emphasizes all three NPPM evaluative dimensions. They develop product roadmaps (balancing product innovativeness, release dates, and resource allocation) for products differentiated through meeting latent customer needs (strategic fit) and that target much higher price points than existing products (financial returns).

\subsection{NPPM at SBU2}

Of the three SBUs we studied, SBU2 was the only firm struggling with poor performance. The within-case write-up summary shows that, while SBU2 had been an industry leader in the past, the competition passed this firm by consistently offering new products. In response to customer demand and corporate mandate, SBU2 recently implemented a fast-follower strategy and has since caught up to the competition by offering the same products as the competition. Informant 3 plays a dominant NPPM role in the idea screening stage because she identifies the list of potential projects that could be developed next. According to the questionnaires, innovation ideas come from the sales force and the firm's direct customers. The interviews reveal that informant 3 attempts to prioritize potential projects based on financial returns in terms of customers' shortterm priorities and identification of the competitors' products that are selling well in the marketplace. She also works within the firm's capacity constraints, and attempts to identify projects that will not be vetoed by senior managers.

Informant 1 dominates the final NPPM approval where the projects that will be implemented are chosen from the list of potential projects identified by informant 3. SBU2's final NPPM approval heavily emphasizes financial returns with short payback periods of two years. Financial expectations are paramount, as the manufacturing services and product management director (informant 1) describes:

[The executive committee] approves [the business plan], which isn't surprise information to them because of communication that goes on and the whole decision making process... They look at costs, ROI, how much time, where is it [going to be produced].

SBU2 differentiates itself from other suppliers by offering fast delivery. The problem is that it must maintain very high inventory levels to implement this service differentiation strategy, which adversely affects its NPPM choices. Informant 1 explains:

We deliver in five days; this does not give room for mistakes in new products, like massive amounts of inventory that doesn't sell. We want to bring out a [product]. We have to have $99 \%$ probability. We may lose sales up front, but that's okay, because we want to make sure it is proven to sell.

The new products launched recently in response to the corporate mandate have created severe inventory and manufacturing capacity constraints. The number of stock keeping units they carry has more than tripled in the past five years and they are operating at $120 \%$ of manufacturing capacity. Now that SBU2 has caught the competition, it is unclear which projects to develop next. As described above, informant 3 identifies potential projects that are feasible given capacity constraints, acceptable to executive managers, and are likely to meet firm and customer requirements. However, balance often is sacrificed as the implementation of some higher-ROI projects has been delayed due to resource constraints.

While their competitive strategy is that of service differentiation, new product projects actually hinder their ability to implement this strategy. Their resource constraints eliminate the ability to consider alternative balance criteria such as technical risk and project return. Their fast-follower competitive strategy is a further constraint in that only incremental projects are implemented. In evaluating new product projects, SBU2 weighs financial returns the heaviest.

\subsection{NPPM at $S B U 3$}

According to the within-case write-up summary, SBU3 has always successfully followed a niche strategy of supplying highprice products that are almost exclusively distributed through a single retail customer. While the firm has always pursued growth through NPD rather than by acquiring other firms, the corporate mandate has encouraged a growing emphasis on introducing new products. This product niche and distribution strategy has been quite successful, as the firm has grown at nearly ten times the industry average over the prior ten years. Even though the managers recognize that broadening their product and customer portfolio could be beneficial, they are implementing changes cautiously. They do not wish to damage their brand equity as a premium brand nor their relationship with their primary customer. 
The surveys reveal that innovation ideas come from key suppliers and from market analysis of the main customers. The technical nature of the product means suppliers offer potential product improvements via modifications in key components. Because the senior managers are all 20-25 year industry veterans, they believe they understand the retailer's needs and can identify viable new product ideas when analyzing main customer market data. Their belief is confirmed by their success in placing products on the retailer's shelves. The senior marketing VP (informant 1) states they have a " $95 \%$ batting average - if we make a product, it gets listed [by the retailer]." Success is achieved by choosing projects pragmatically, developing lower-return, higher-probability of retailer adoption opportunities over higher-return, lower-probability of adoption alternatives.

The strategic fit of projects also is evaluated in terms of the brand equity impact, with the strategy of developing only premium products. The technology and purchasing senior VP (informant 2) explains:

One of the key features about our company is that we've done everything pretty much with one price point. This is totally, totally contrary to what other people do. ...All you have to do is look at the car companies. GM makes a Cadillac and then says, "Not everybody is going to buy a Cadillac." ...So, what do they do? They make a Buick. Good car, same class, same engine, but a little more plastic, the other one is a little more leather. So, all of a sudden, you have a lower price point, right? Not everybody is going to buy a Buick, so now, they are going to have to make something even lower priced. This is exactly how big business is. ... We haven't done that here.

Technical feasibility also is evaluated. Prior to allocating resources to develop a project, $R \& D$ assesses if the technology is sufficiently developed to deliver the customer benefits in a timely manner. Not all projects require technical feasibility studies because, for some projects, feasibility is readily apparent. Technical feasibility is a component of balance because it is how this firm assesses technical risk. Managers at this SBU, however, evaluate no other component of balance for the projects that do not require a feasibility analysis.

Thus, the brand equity impact (strategic fit) and technical feasibility (balance) act as hurdles for all projects: only technically feasible projects that fit the brand image are considered for development. However, the dimension afforded the highest weight in project selection is that of financial returns in terms of likely revenue. To select projects, SBU3 evaluates the financial returns in terms of forecasted demand volume, as informant 2 describes:

We look at the potential of the project, which is quite simple. We write down A, B, C on the project and it's based on volume and there is a million dollar potential. Below that, the next level, B. And the $\mathrm{C}$ can be a lower volume but strategically an important project. It can fit with our program, but not necessarily have a lot of volume.
Project selection happens informally. Informant 2 explains, "We are very informal about all this. If I want to talk to anybody in this company, I don't normally wait for the meeting; I go down and talk to them." The senior executives, including the two informants we interviewed, decide which projects to implement. Thus, at SBU3, dominance in NPPM decisions is shared.

\section{Managers' dispositions}

As the literature provided little direction regarding the specific dispositions that operate within the context of the mandated change in innovation strategy, we analyzed the transcripts and field notes to identify and categorize the informants' revealed personality traits. Four dispositions stood out: change resistance, ambiguity tolerance, analytic cognitive style, and leadership style. Change resistance is an individual's tendency to resist or avoid making changes, to devalue change generally, and to find change aversive across diverse contexts and types of change (Oreg, 2003). This construct consists of four factors: routine seeking, negative emotional reaction, short-term thinking focusing on the immediate inconvenience or adverse effects, and closed-mindedness. Change resistance is moderately negatively correlated with ambiguity tolerance (Oreg, 2003).

Ambiguity tolerance represents a person's capacity to accept the absence of information about the range and probabilities of possible outcomes (Sherman, 1974). Those low in ambiguity tolerance perceive ambiguous situations as sources of threat, while those high in ambiguity tolerance perceive such situations as non-threatening (Budner, 1962). Ambiguous situations include completely new situations, complex situations where there are a great number of cues, or contradictory situations (Conchar, Zinkhan, Peters, \& Olavarrieta, 2004). Given this definition, NPPM decisions clearly fall within the category of ambiguous situations. People who are less tolerant of ambiguity are likely to gather more information during the decisionmaking process, to consider ambiguous situations as more risky, and to be less willing to take risks (Conchar et al., 2004).

Analytic cognitive style is the consistent manner in which individuals approach perceptual and intellectual activities such as problem-solving (van Bruggen, Smidts, \& Wierenga, 1998). Individuals' analytic cognitive style in problem solving can be described on a continuum anchored by low-analytic and highanalytic. Those who are low-analytics tend to consider problems in a holistic manner, looking for workable solutions to total problem situations. As a result, they search for analogies with familiar, solved problems to adopt that solution. Highanalytics, on the other hand, tend to reduce problems to a core set of underlying causal relationships and parameters. Such individuals try to detect cause-effect relationships and then manipulate the decision variables to reach the best outcome.

Leadership style is the extent to which leaders behave democratically or autocratically (Eagly \& Johnson, 1990). In democratic leadership styles, leaders allow subordinates to participate in decision making, trying to build consensus around the best choice. In autocratic leadership, subordinates are discouraged from participating in decision-making and are 
expected to implement the choice without question. Eagly and Johnson's (1990) meta-analysis finds that women tend to adopt a more democratic leadership style than men.

\subsection{Manager dispositions at SBU1}

The manager dispositions for SBU1, along with data supporting the classifications, are presented in Table 4. The quotes in the tables represent exemplary quotes revealing the managers' dispositions. The first informant is the marketing and product development VP. As shown previously in Table 1, this informant is new to the firm having come from a firm in the same industry that targeted consumers rather than targeting intermediaries as does SBU1. This informant is not resistant to change, as might be expected from a person who voluntarily changed jobs. Given his consumer-oriented background, he is comfortable with ambiguous situations as is generally the case when soliciting customer information to develop non-incremental innovations. He asserts that ideas do not come neatly packaged from customers; interpreting customer needs into clear and thorough product descriptions is the firm's job. As a high analytic, this informant is comfortable specifying the parameters for the development team so they can develop the project within the market window. His leadership style is moderately democratic in that he recognizes the value of consensus-building, and realizes that this leadership style takes more time than simply dictating policy. Informant 1 dominates NPPM decisions via his role as a member of the executive committee.

The second informant at SBU1 is the product development and engineering senior director. Because informant 2 has been with the firm and holding company for considerable time, he has strong informal networks and considerable knowledge of the firm's culture. This informant's change resistance is low, as he voices no resistance to the corporate directive to implement new software despite the fact that SBU1 had no input into the decision and the possibility of the software failing to satisfy SBU1's needs. Furthermore, his ambiguity tolerance is high. He implicitly juxtaposes his own lack of fear regarding ambiguous communication tools with others who are reluctant to use them. This informant is a high analytic. In implementing the corporate-mandated software, he is thoroughly reviewing the specifications and implications so that the implementation proceeds smoothly. This informant exhibits democratic leadership style in his concern for the employees: he wants the changes to be implemented so that the employees see the benefits and embrace the change. Informant 2 is not involved in NPPM decisions and so does not have a dominant role.

Table 4

Manager characteristics and supporting data (i.e., exemplary statements) at SBU1

\begin{tabular}{lll}
\hline Informant & Change Resistance (high to low) & Ambiguity Tolerance (high to low) \\
\hline 1 & Low & \\
In response to: How do you find & "Aigh & "A lot of our categories are very \\
the employees and managers are & mature and there certainly isn't a lot \\
coping with the changes? "I don't & of innovation so I don't expect \\
have any resistance. I'm getting & ideas to come neatly packaged from \\
resistance to change." & $\begin{array}{l}\text { the customer in these categories. In } \\
\text { the innovation I thought about it as } \\
\end{array}$ & $\begin{array}{l}\text { more we are going to create what } \\
\text { they don't know they want yet." }\end{array}$
\end{tabular}

"We are looking at other [information technology] tools as well. One of them is contact management with [software], and that was kind of a directive we got from [corporate]. So we will use [software] to align with other [corporate] divisions and how we share content with key customers."
High

"I still think there is that fear factor of video conferencing: 'We never get it to set up correctly.' Net meetings: 'You still need an ISP and I can't get it to run.' What is really happening is that stuff is going away and it will be really intuitive. You'll walk into this application that looks like an email and you'll be able to drop and add files and it will look like a share drive, notes, or email. It will look like the Internet. But nobody is comfortable with that. Once it becomes intuitive, it will explode."
Analytic Cognitive Style

(high to low analytic)

High

"I come to them and say I need a [product with specific parameters]. I'm giving them all these parameters so they are more focused and they develop quickly The previous process, because it didn't have a definition, just took way too long and they were missing too many opportunities. The opportunity would be there when they began but by the time the product came out the opportunity need had changed. So, they were very inconsistent in terms of time." High

"We may look at collaborative

Leadership Style

(autocratic vs. democratic)

\section{Moderately democratic}

"There is a way we work here that I think it's good but I think it's slow. The way we do things we build consensus and get by. That's important because we don't have every department do it. But it's slower to win people over. I used to work at other places to where we used to get rid of top-level people and start on day two. Those weren't places that I'd send you to work, either. This place here is a lot more considerate of the employees and their attitudes and so forth."

Democratic

"Our people are our biggest design tools and we haven't yet because we've got to do one thing first before we do the others. We've got to do a gap analysis of, okay, here is where [software] will work with us, our content manager, the catalogues, working with our major customers, and here is when we get our transaction and execution date.' challenge. Our 2-3 year vision is training these folks, support these folks, coach these folks, and develop leaders within the organization throughout the product development function. Bring people that can do that and infuse skills where we don't have them. ...we have to train people how to use these tools, we've got to make it part of our culture, we've got to learn what works well with them and what doesn't." 


\subsection{Manager dispositions at SBU2}

Table 5 lists the SBU2 manager dispositions and data supporting the classifications. The director of manufacturing services and product management plays a dominant role in portfolio management because he acts as a gate keeper by insisting that only proven projects with " $99 \%$ probability" of success are developed. While he has been with the firm some time, approximately half of his experience was as a plant manager, with prior automotive manufacturing experience. With this background, an adversarial management style is expected and in fact is exhibited in his autocratic leadership style. Despite this background, however, he exhibits low change resistance as he compares his acceptance of customers' changing attitudes with that of the manufacturing plant employees' resistance. This informant's ambiguity tolerance is low: selecting new products to develop without the luxury of mimicking competitors is uncomfortable. Regarding analytic cognitive style, we categorize this manager's style as high analytic because he has intimate knowledge of all the details associated with NPD and has worked with the program manager in implementing the new NPD process.
SBU2 uses project management software that details all the components of each stage and gate, along with the critical path. Given his extensive background with NPD and project management software, the second informant was hired to implement project management software to support the new NPD process SBU2 had implemented. As he was hired to implement the SBU's substantial change in NPD, we expect this informant's change resistance to be low. Indeed, the supporting quote in Table 5 suggests informant 2 understands that the magnitude of the change could result in slow implementation. His democratic leadership style, as reflected in his assessment of his "customers" needs, has enabled him to design the process to increase buy-in among users. Given the complications of the process, his high analytic cognitive style has been useful in creating a comprehensive tool to manage and communicate the NPD process. However, he exhibits low ambiguity tolerance in that he strongly dislikes the lack of information regarding what they will work on next. Informant 2 is not involved in NPPM decisions and so does not have a dominant role.

The final informant is the senior product manager who has lengthy tenure with SBU2. Informant 3 is the only woman among the seven managers we interviewed. She has extensive

Table 5

Manager characteristics and supporting data (i.e., exemplary statements) at SBU2

\begin{tabular}{|c|c|c|c|c|}
\hline Informant & Change resistance & Ambiguity tolerance & Analytic cognitive style & Leadership style \\
\hline 1 & $\begin{array}{l}\text { Low } \\
\text { "A lot of it is explaining to the } \\
\text { manufacturing companies why } \\
\text { we are doing this, because they } \\
\text { don't see it. The manufacturing } \\
\text { companies say, "We've always } \\
\text { done it this way. Why are we } \\
\text { changing and causing all this }\end{array}$ & $\begin{array}{l}\text { Low } \\
\text { "I think we have caught up with } \\
\text { the competition; a lot of the low } \\
\text { hanging fruit is being eliminated. } \\
\text { We now have to slide down that } \\
\text { curve slightly and become a little } \\
\text { more innovative. That is scary to } \\
\text { us because that is not what we like }\end{array}$ & $\begin{array}{l}\text { High } \\
\text { "We communicate through a } \\
\text { business plan. That business plan } \\
\text { begins in our marketing } \\
\text { department. ... They take what the } \\
\text { industry needs, prototype them, send } \\
\text { them to the customer, get feedback } \\
\text { back, then we give that to }\end{array}$ & $\begin{array}{l}\text { Autocratic } \\
\text { "It is also holding people } \\
\text { accountable and understanding } \\
\text { that there will be a price to pay if } \\
\text { you don't do a good job. We have } \\
\text { terminated engineers for not being } \\
\text { able to adapt. ... And that is } \\
\text { just a necessary evil." }\end{array}$ \\
\hline
\end{tabular}
headache?" We are finally to do but that is what we are doing."

latching on to the fact that our customer is having a tremendous change in their attitude and they are more accepting to it."

Low
"Because we are dealing with people and changing the culture, it is generally working; we are progressing and doing things we have never done."
Low

"We don't have the drop in the idea, turn the crank and it's a green light or a red light, we are going to do it or we aren't going to do it, although it should allow us to do that.... We are almost at an impasse ... and we don't like that."

\footnotetext{
Low

"Some of these we've identified in the last month or so and they've actually moved up to number 1 priorities... So, we've got to actually rush to get a program together... But, all of that works towards our overall company strategy of building the [customers'] business."
}

High Low

"Trying to figure the [customers] out "We have 3 collections and 3 is a so that's going to help us in our new pretty good number. We didn't want 5 , product strategy. Very, very much so you never want 4 , so 3 works for me!' trying to find out what the important "[The front end] has so many things things are that people look at and how that actually could be done, but they much time they spend [looking at don't all need to be done all the time. products] and things like that. So that There are different ways to do them can help us create new products." probably every time. To map that out...I think it is very difficult."
Democratic

"When I first started in this job, I interviewed people who were involved with the process. I found out the issues from their perspectives. It is simplistic but easy to scope a problem/solution if I view things as marketing, as my customer, just tell me what you want. And I can give it to you and tell the data/plant people what I need to give the customer what they need."

Democratic

"[The happy hour] did a lot of good [by increasing informal communication]... Which I think is really good because even if you aren't getting anything accomplished for work, I think it still drives a lot of that camaraderie and team building. Which, I think, in the long run could accomplish more than shoving meetings at people." 
experience in marketing and design positions emphasizing creativity, so it is not surprising that her ambiguity tolerance is high. She shows no discomfort in analyzing ambiguous customer input to identify opportunities for new products. Her cognitive style is low analytic, as she finds it difficult to map her decision process in the fuzzy front end. However, she does not resist change. Even when last minute priority changes mean she has to rush her work, she focuses on the change benefits to the firm. As expected from the Eagly and Johnson (1990) metaanalysis, her leadership style is democratic. She tries to build consensus by using outside-of-work get-togethers to enhance informal communication channels. Given her role in assembling the list of potential new product projects, this informant dominates the initial NPPM step.

\subsection{Manager dispositions at SBU3}

Manager dispositions for the final SBU, SBU3, along with the supporting data for the classifications, are listed in Table 6. The first informant is the marketing senior vice president, who has been with the firm a relatively short time. This informant's entire career has been in SBU3's industry, thus he has considerable industry knowledge of both the customers and the technology. He spent several years with an electronic commerce start-up firm prior to joining SBU3. The field notes (this informant declined our request to tape the interview) suggest that informant 1's change resistance is low, as he told us he has experience with change and he expects that experience to be useful in implementing a formal NPD process. His ambiguity tolerance is low, as he does not express concern about the substantial changes that will be brought about by upcoming regulatory and technological changes in the industry. Informant 1 's analytic cognitive style appears to be that of a low analytic, as he considers himself to be an industry expert and so detailed opportunity analysis is unwarranted. This informant exhibits a democratic leadership style. He understands SBU3's informal culture is creating resistance to formal NPD process implementation, and is planning ways to build consensus regarding the need for process formalization. Finally, this informant plays a dominant role in NPPM decisions as these decisions are made by the senior managers from sales, marketing (this informant), and technology and purchasing (informant 2).

The second informant from SBU3 is the senior vice president of the R\&D department and the technical purchasers. Similar to the first informant, his entire career has been in technical positions in this SBU's industry, so he has considerable technical knowledge. He has been employed at SBU3 for over a dozen years and, based on the data, is resistant to change as he is unwilling to modify the development strategy of making the best product in the category, which he considers to be his prime

Table 6

Manager characteristics and supporting data (i.e., exemplary statements) at SBU3

\begin{tabular}{|c|c|c|c|}
\hline Informant & Change resistance & Ambiguity tolerance & Analytic cognitive style \\
\hline 1 & $\begin{array}{l}\text { Low } \\
\text { Informant has the mandate to } \\
\text { implement a formal NPD process. } \\
\text { He has experience with change, } \\
\text { which he expects will be helpful } \\
\text { in implementing the change to a } \\
\text { formal NPD process. }\end{array}$ & $\begin{array}{l}\text { Low } \\
\text { Impending regulatory changes and } \\
\text { new technology (e.g., } \\
\text { nanotechnology) are expected to } \\
\text { generate a lot of innovations. The } \\
\text { informant does not know what } \\
\text { nanotechnology will bring } \\
\text { specifically, but he expects lots of } \\
\text { product opportunities. }\end{array}$ & $\begin{array}{l}\text { Low } \\
\text { Portfolio management choices } \\
\text { are made informally by the } \\
\text { senior executives, who are all } \\
20-25 \text { year industry veterans. } \\
\text { Their decision making is } \\
\text { "largely intuitive," occurring in } \\
\text { a "4 minute conversation" in } \\
\text { the hallway. They look at the } \\
\text { retailer's product assortment to } \\
\text { identify gaps. Given the } \\
\text { informants' industry } \\
\text { background, they are able to } \\
\text { make educated guesses. }\end{array}$ \\
\hline
\end{tabular}

2 High

"When I was brought into this business, at the time I reported to the two people who owned the company. And they said my job was to make the best product in the category. Don't worry about the cost. Don't worry about selling it because we will sell it... That is exactly what I was told from day one. The president now is the fourth boss I've had. I didn't change. They changed, but nobody has changed [my instructions]. So I'm still operating on that one principle."

\section{Low}

"I would like to have [the sales forecast] but we don't quite have it, but we have a general idea. The problem there is this: until the product has been developed and the final presentation has been made to the customer, we don't know what the customer is going to do and that's good and bad... It's a big investment and it's a brand new product with a brand new [component] and a lot of brand new technology in it. It was so risky. I advised our company never, never again. To the point to where if we ever do that I will not support it."

\section{Low}

"[Portfolio management is] not all science. Sometimes it is a lot of gut feelings and visions and stuff like that." From field notes due to recording failure: The NPD process needs to be improved, but he doesn't want

to be a slave to the process. If you have simple principles, life is easy. He falls back to his prime directive to make the best product in the category. The problem in his department is lack of process. He sees how process can make life easier.
Leadership style

Democratic

Everybody is ready for a clean definition of steps in the NPD process. The organization needs something like this. Two years ago it wouldn't have been ready. However, this informant expects there will be a culture shock ("there will still be a lot of screaming, because the days of shooting from the hip with intuition will be over"). To get buy-in to the change among senior managers, he hired a top consultant to present the "why and how" of formal NPD processes. Autocratic

"We are very informal about all this. If I want to talk to anybody in this company, I don't normally wait for a meeting. I go down and talk to them. ... I'm not trying to be funny about it but that's the nature of the entrepreneurial culture we have. We don't want to change that." "By being an entrepreneurial company, we aren't as structured as one might expect. We are getting more structured, and we are trying to do that, and we have absolutely no apology for not being too structured." 
directive. This manager also exhibits low ambiguity tolerance, as he is quite uncomfortable with the lack of early customer commitment to the products his department is developing. His analytic cognitive style appears to be that of a low analytic, as he prefers to operate within simple principles like the prime directive. Furthermore, he concludes that NPPM is holistic rather than consisting of individual parts that can be independently assessed. Finally, this informant exhibits an autocratic leadership style when he discusses how the portfolio management decisions are made. Only he (as the senior manager of the R\&D department) and the senior managers of the sales and marketing function are involved in these decisions, with no input from other functional groups. As the quotes in Table 6 indicate, he and the other senior managers communicate in an informal and unstructured manner as they make NPPM decisions. However, the communication is limited to senior managers. Nowhere does this informant discuss the need to get buy-in from his subordinates or other functional groups.

Table 7 presents a summary of all the manager dispositions and their level of dominance in the NPPM decisions. In the next section, we develop propositions relating managers' dispositions to the NPPM evaluative dimensions used at each SBU.

\section{The effect of managers' dispositions in new product portfolio management}

\subsection{Financial returns dimension}

Prior research documents that financial returns is the dimension most often used by managers when evaluating new product projects (Cooper et al., 1999; Tzokas et al., 2004). Consistent with this result, in all three SBUs we studied, financial returns are evaluated when choosing the new product projects to fund. Due to this dimension's use in all three cases, our data do not provide enough evidence to relate manager characteristics to the NPPM financial returns dimension. Nonetheless, it is worthwhile to note an observation gleaned in these cases. SBU2 is the only firm that has poor performance. In addition, SBU2 weighs financial returns very heavily in both project identification and
Table 8

Relating analytic cognitive style to balance

\begin{tabular}{lll}
\hline SBU & $\begin{array}{l}\text { Dominant manager's } \\
\text { analytic cognitive style }\end{array}$ & Balance \\
\hline SBU1 & High & $\begin{array}{l}\text { Develop 3-5 year product roadmaps } \\
\text { (systematic and balanced progression of } \\
\text { the product lines) that balance product } \\
\text { innovativeness and release dates }\end{array}$ \\
SBU2 & Informant 3: Low & $\begin{array}{l}\text { Struggles with NPPM project specification } \\
\text { step due to resource constraints } \\
\text { Only criteria used is technical feasibility, } \\
\text { which functions solely as a hurdle }\end{array}$ \\
SBU3 & Low & \\
\hline
\end{tabular}

selection, almost ignoring other elements such as strategic fit. Research suggests, however, that performance is enhanced when multiple portfolio management dimensions are used (Baker \& Albaum, 1986; Cooper et al., 1999). Our study results are consistent with this finding.

\subsection{Balance dimension}

The balance dimension helps ensure that the project portfolio is not skewed excessively towards any project category. Achieving balance is difficult because (among other reasons) there are multiple concerns to balance, such as time frame, technical risk, project innovativeness, resource availability, return, etc. Several mechanisms have been suggested to evaluate multiple projects according to various concerns, including bubble diagrams, scoring models, checklists, and decision support systems such as analytic hierarchy process (Calantone, Di Benedetto, \& Schmidt, 1999; Chien, 2002; Cooper et al., 2001a). In our cases, SBU2 and SBU3 do not effectively use the balance criterion. SBU2 struggles to identify projects that match all the constraints, while SBU3 solely evaluates technical feasibility in the balance dimension and only as a hurdle. SBU1 uses product roadmaps to balance project innovativeness and release date while also ensuring resource availability. Product roadmaps force firms to schedule projects by project type at evenly spaced intervals to ensure a steady stream of new products (Wheelwright \& Clark, 1992). Although not used

Table 7

Summary of manager dispositions

\begin{tabular}{|c|c|c|c|c|c|c|c|}
\hline SBU & Informant & Title & $\begin{array}{l}\text { Dominant } \\
\text { decision-maker? }\end{array}$ & $\begin{array}{l}\text { Change resistance } \\
\text { (high to low) }\end{array}$ & $\begin{array}{l}\text { Ambiguity tolerance } \\
\text { (high to low) }\end{array}$ & $\begin{array}{l}\text { Analytic cognitive style } \\
\text { (high to low analytic) }\end{array}$ & $\begin{array}{l}\text { Leadership style } \\
\text { (autocratic vs. democratic) }\end{array}$ \\
\hline \multirow[t]{2}{*}{ SBU1 } & 1 & $\begin{array}{l}\text { VP of Marketing and } \\
\text { Product Development }\end{array}$ & Yes & Low & High & High & Moderately democratic \\
\hline & 2 & $\begin{array}{l}\text { Sr. Dir. of Product } \\
\text { Development and } \\
\text { Engineering }\end{array}$ & No & Low & High & High & Democratic \\
\hline \multirow[t]{2}{*}{ SBU2 } & 1 & $\begin{array}{l}\text { Dir. of Mfg. Services } \\
\text { and Product Management }\end{array}$ & Yes & Low & Low & High & Autocratic \\
\hline & 3 & Sr. Product Manager & $\begin{array}{l}\text { Yes (specifies } \\
\text { potential projects) }\end{array}$ & Low & High & Low & Democratic \\
\hline \multirow[t]{2}{*}{ SBU3 } & 1 & Sr. VP of Marketing & Yes & Low & Low & Low & Democratic \\
\hline & 2 & $\begin{array}{l}\text { Sr. VP of Technology } \\
\text { and Purchasing }\end{array}$ & Yes & High & Low & Low & Autocratic \\
\hline
\end{tabular}


extensively, product roadmaps are associated with improved NPD performance (Cooper et al., 2004b).

Given the complexity of balancing multiple concerns, we might expect that analytic cognitive style plays a role because it relates to the ability to break down complex problems into components and evaluate each component's impact. Our data reveal such a linkage (see Table 8). Where the managers exhibit high-analytic cognitive style (in SBU1), product roadmaps are used. At SBU2, the senior product manager dominates the NPPM potential project specification and exhibits low analytic cognitive style. She finds it difficult to map her portion of the NPPM process. At SBU3, both informants who dominate NPPM decisions exhibit low analytic cognitive style, making NPPM decisions in an intuitive, informal, and holistic manner. Thus, our qualitative data suggest that managers' analytic cognitive style is linked to their approach to the balance dimension, as formally stated in the proposition below.

P1. The more analytic the cognitive style, the more likely the balance dimension will exhibit detailed evaluation of multiple criteria.

\subsection{Strategic fit dimension}

The strategic fit dimension helps ensure that the projects in the portfolio reflect the firm's strategy and objectives. While managers generally report modest success on this dimension, there is room for improvement in using NPD to grow into new product categories and unserved markets (Cooper et al., 2004a). Moving away from the incremental innovations typical of serving existing markets and improving existing product lines requires high ambiguity tolerance because market information is unclear and even lacking. Identifying non-incremental new product opportunities in existing markets requires addressing latent customer needs. It also requires a leap of faith because it is very difficult to predict the acceptance of non-incremental innovations (Hoeffler, 2003).

In our cases, the managers' NPD focus is on new products for their existing customers, but varies in their examination of latent customer needs (see Table 9). Informant 1 at SBU1 explicitly identifies the need to understand and interpret customers' needs, as he does not expect ideas to come "neatly packaged." The SBU2 and SBU3 managers hold the opposite view: customers are not "proactive thinkers," and "taking information from customers is never innovative." While informant 3

Table 9

Relating ambiguity tolerance to strategic fit

\begin{tabular}{lll}
\hline SBU & $\begin{array}{l}\text { Dominant manager's } \\
\text { ambiguity tolerance }\end{array}$ & Strategic fit \\
\hline SBU1 & High & $\begin{array}{l}\text { Addressing latent customers needs (create } \\
\text { what they do not yet know they want). } \\
\text { Customer feedback on short-term needs only } \\
\text { (do not examine latent needs) } \\
\text { SBU2 Informant 1: Low }\end{array}$ \\
SBU3 Low & $\begin{array}{l}\text { Develop premium brands the retailer will } \\
\text { adopt (do not examine latent needs) }\end{array}$ \\
\hline
\end{tabular}

Table 10

Relating leadership style to dimension weighting

SBU Dominant manager's Dimension weighting leadership style

SBU1 Democratic Equal

SBU2 Informant 1: Financial returns heaviest Autocratic

SBU3 Informant 1: Democratic Informant 2 : Autocratic

Strategic fit and balance are used as hurdles only. Financial returns are most heavily weighted in project selection due to Informant 2's past experience with an unsuccessful product

at SBU2 exhibits high ambiguity tolerance and identifies innovative projects, SBU2's informant 1 (who dominates NPPM decisions and exhibits low ambiguity tolerance) acts as a gate keeper by ensuring only proven projects are developed. Thus, our qualitative data suggest that managers' ambiguity tolerance is linked to their approach to the strategic fit dimension, as formally stated in the proposition below.

P2. The higher the ambiguity tolerance, the more likely the strategic fit dimension will involve examination of latent customer needs to develop non-incremental new products.

\subsection{Evaluative dimension weighting in new product portfolio management}

While three evaluative dimensions are used to manage new product project portfolios - value maximization, balance, and strategic direction - the weight or emphasis given to each varies considerably across firms (Baker \& Albaum, 1986; Cooper et al., 1997a; Ronkainen, 1985). Over-emphasizing one dimension, such as evaluating only financial returns, is linked with poorer performance (Baker \& Albaum, 1986; Cooper et al., 1999). Regarding managers' dispositions, leadership style is important in creating a climate of quality in R\&D departments (Berson \& Linton, 2005). Furthermore, aspects of a democratic leadership style have been associated with improved NPD performance. Specifically, open communication among employees across functions, departments, and locations helps stimulate creativity and permits more effective communication within NPD teams, while senior management delegating day-today activities and decisions in NPD projects to team leaders and members helps improve new product project performance (Cooper et al., 2004a).

Our data reveal a linkage between managers' leadership style and the weighting of NPPM dimensions (see Table 10). Where the managers exhibit a democratic leadership style (in SBU1), the criteria merit equal importance. At SBU2, informant 2 exhibits an autocratic leadership style and dominates NPPM decisions by acting as a gate keeper to limit new projects to those with very high success probabilities. At SBU3, informant 1 exhibits a democratic leadership style and, along with the other managers, identifies the projects to be developed. Informant 2 also dominates NPPM decisions via gate keeping through change resistance. He particularly resists NPD process changes that may limit his authority to run the R\&D department. 
The data from managers exhibiting a democratic leadership style suggest they include others in decision-making due to their involvement in implementing the resulting choice. For example, informant 2 at SBU1 discusses the importance of the firms' employees in implementing the new NPD processes. He identifies that the employees not only need to be trained, but that they need to be coached through the change to infuse them with new skills. Informants 2 and 3 at SBU2, who also exhibit a democratic leadership style, see the value to the firm of creating team camaraderie and implementing changes that account for the specific needs of those involved. At SBU3, informant 1 exhibits a democratic leadership style and explicitly highlights the role of time for employees to adjust when implementing change.

Our qualitative data suggest that managers' who are attuned to the needs of those impacted by NPPM decisions and the time it takes to implement associated changes, incorporate the needs of these employees in the NPPM dimensions. They try to balance resources and time commitments by evaluating multiple criteria in the balance dimension. They also take a longer-term approach to NPPM by considering the timeframe required to effectively implement change. This longer-term perspective has been useful at SBU1, which is implementing NPPM to not only improve financial returns but also to fit with its product differentiation strategy. SBU2 takes a short-term approach and is experiencing poor performance as a result. Thus, leadership style is linked to managers' weighting of the NPPM evaluative dimensions, as formally stated in the proposition below.

P3. The more democratic the leadership style, the more likely the NPPM evaluative dimensions will exhibit equal weighting.

\section{Theoretical and managerial implications}

The major theoretical contribution of our study is that we link managers' dispositions with the use of NPPM evaluative dimensions. Past research has identified that differences exist between personality traits of marketing and $R \& D$ personnel (Lucas \& Bush, 1988). These differences may cause problems such as poor communication and conflict between NPD team members during the progression of an NPD project. Such problems significantly hinder operational outcomes such as meeting project deadlines and maintaining budgetary limits. Our results suggest the influence of personality traits on which new product projects firms choose to develop. By shaping the relative importance of NPPM evaluative dimensions, managers' dispositions ultimately affect a firm's new product portfolio and its long-term success in the marketplace.

A unique contribution of our findings is identification of specific personality traits influential in NPPM. We find evidence that managers' analytic cognitive style, ambiguity tolerance, and leadership style are related to certain NPPM dimensions and the importance afforded to each dimension. Specifically, we find that analytic cognitive style is associated positively with balance. The balance dimension often is evaluated through the use of diagrams, such as pie charts and bubble diagrams. However, the use of such charts can be problematic because it is not clear which information to profile in the charts and information overload can occur due to diagram proliferation (Cooper et al., 2001b). Interestingly, the SBUs we study do not employ such diagrams. Instead, SBU1 employs product roadmaps despite their not being used extensively. The benefit of product roadmaps is that they force firms to evaluate multiple criteria and choose the projects to develop over an extended future timeframe. Doing so not only ensures a steady stream of new products (Wheelwright \& Clark, 1992), it also forces firms to identify their strategies and agree upon priorities to achieve those strategies. Choosing the most important evaluative criteria within the balance dimension is detailed work at which those high in analytic cognitive style thrive.

Our results also indicate that ambiguity tolerance is positively associated with the NPPM dimension of strategic fit. While managing product development effectively is crucial in delivering customer value (Srivastava et al., 1999), and perusal of any current business-focused magazine attests to the importance of innovation in firm performance, firms still struggle to find NPD success (Griffin, 1997). A primary benefit of innovation and NPD is delivering superior customer value through differentiation, which requires a deep understanding of customers' latent needs. While managers operating in a businessto-business environment may not typically evaluate customers' latent needs, the research results indicate the strategic value of doing so. Our results suggest that intolerance of the types of ambiguous information derived from assessing latent needs is associated with weak strategic fit and a short-term view in project selection. The short-term view exacerbates poor performance results due to opportunity costs and lower-than-optimal profits. By taking a longer-term approach and looking for latent customer needs, firms can develop differentiated products that meet a real market need and sell at prices that enable a reasonable profit.

The research results also indicate that managers' leadership style is positively associated with how much importance or weight they place on each evaluative dimension. As leadership style involves the extent to which subordinates are involved in decision-making, our empirical result would have been difficult to hypothesize deductively from extant literature. Prior research suggests only that delegating day-to-day activities to NPD teams (a behavior that may be correlated with a democratic leadership style) is associated with NPPM success (Cooper et al., 2004a). However, the findings tend to suggest a relationship between managers' leadership style and the importance or weight placed on each evaluative dimension, demonstrating the appropriateness of our research case study approach.

Finally, our data reveal no association between managerial dispositions and the NPPM evaluative dimension of financial returns. Consistent with prior research documenting the prevalence of financial returns assessment in NPPM, financial returns are evaluated in all three SBUs we studied when choosing the new product projects to fund. The lack of an association for the financial returns dimension with manager dispositions reveals a boundary condition for the role of dispositions in NPPM 
decisions. Given the primary objective of industrial firms to produce a profit, the influence of individual-level factors is minimal in comparison with this firm-level objective.

This research is important for managers because of the impact of NPPM on firm performance and because of the variability of dispositions across managers. Firms implementing better portfolio management reap substantial performance rewards, and yet there remains considerable variability in best practices implementation for NPPM across firms (e.g., Cooper et al., 2004a). In today's competitive environment, NPPM process improvements can result in sustainable competitive advantage by increasing the likelihood of selecting new product projects that will generate successful new products. As our research suggests, managers' dispositions are one factor potentially limiting firms' improvements. As such, managers should be attuned to their own and their colleagues' dispositions so that roadblocks to successful implementation of effective NPPM processes can be overcome.

Required managerial behaviors should change in a manner consistent with the needs of the new strategy, as when moving from a growth to a turnaround strategy (Hofer, 1980; Szilagyi \& Schweiger, 1984). Our research supports this argument that executives should consider managers' dispositions when evaluating job assignments in NPPM roles. For example, firms may choose to compete through consistent new product introductions and development (or maintenance) of a reputation as an innovative company. In this scenario, managers involved in NPPM should be aware of the ambiguity tolerance levels of decision makers and the adverse effects of intolerance. Where it is not possible to choose managers high in ambiguity tolerance, the existing managers should implement procedures that do not allow them to circumvent assessment of latent customer needs and other relevant information that is difficult to interpret.

Regarding future research, the literature review suggests a lack of theoretical explanations to identify which specific dispositions are operational in NPPM processes. While this exploratory research suggests four dispositions, future research may find it fruitful to investigate other manager dispositions that might potentially play a determining role in NPPM decisions. For example, organizational change research reveals that having a positive self concept, which consists of locus of control, generalized self-efficacy (GSE), self-esteem, and positive affectivity, is positively associated with managers' ability to cope with organizational change (Judge et al., 1999).

Future research should not only investigate additional dispositions, but also should attempt to contribute to the ongoing debate about the relationships within personality traits. Core self-evaluation theory suggests that GSE and self-esteem load on a higher-order factor (together with neuroticism and locus of control), and hence should be treated as a unitary construct (Judge, Locke, \& Durham, 1997). Other research suggests that GSE and self-esteem are conceptually distinct constructs, and that GSE is more highly related to motivational variables than is self-esteem while self-esteem is more highly related to affective variables than is GSE (Chen, Goddard, \& Casper, 2004). Future NPPM research should examine these dispositions to explicate not only their impact on NPPM decisions but also further explicate how they relate to each other.

\section{References}

Adams-Bigelow, M., Kleinschmidt, E. J., Kuczmarski, T. D., Notargiacomo, R., \& Peters, L. S. (2006). Rejoinders to "Establishing an NPD best practices framework." Journal of Product Innovation Management, 23(2), $117-127$

Baker, K. G., \& Albaum, G. S. (1986). Modeling new product screening decisions. Journal of Product Innovation Management, 3(1), 32-39.

Baker, N. R. (1974). R\&D project selection models: An assessment. IEEE Transactions on Engineering Management, 21, 165-171.

Berson, Y., \& Linton, J. D. (2005). An examination of the relationships between leadership style, quality, and employee satisfaction in R\&D versus administrative environments. $R \& D$ Management, 35(1), 51-60.

Bonoma, T. V. (1985). Case research in marketing: Opportunities, problems, and a process. Journal of Marketing Research, 22(2), 199-208.

Budner, S. (1962). Intolerance of ambiguity as a personality variable. Journal of Personality, 30, 29-50.

Calantone, R. J., Di Benedetto, C. A., \& Schmidt, J. B. (1999). Using the analytic hierarchy process in new product screening. Journal of Product Innovation Management, 16, 65-76.

Caldwell, S. D., Herold, D. M., \& Fedor, D. B. (2004). Toward an understanding of the relationships among organizational change, individual differences, and changes in person-environment fit: A cross-level study. Journal of Applied Psychology, 89, 868-882.

Callaway, M. R., Marriott, R. G., \& Esser, J. K. (1985). Effects of dominance on group decision making: Toward a stress-reduction explanation of groupthink. Journal of Personality and Social Psychology, 49, 949-952.

Carbonell-Foulquie, P., Munuera-Aleman, J. L., \& Rodriguez-Escudero, A. I. (2004). Criteria employed for go/no-go decisions when developing successful highly innovative products. Industrial Marketing Management, 33(4), 307-316.

Cattell, R. B. (1943). The description of personality: Basic traits resolved into clusters. Journal of Abnormal and Social Psychology, 38, 476-506.

Cattell, R. B. (1945). The description of personality: Principles and findings in a factor analysis. American Journal of Psychology, 58, 69-90.

Chen, G., Goddard, T. G., \& Casper, W. J. (2004). Examination of the relationships among general and work-specific self-evaluations, work-related control beliefs, and job attitudes. Applied Psychology: An International Review, 53(3), 349-370.

Chien, C. (2002). A portfolio-evaluation framework for selecting R\&D projects. $R \& D$ Management, 32(4), 359-368.

Chiu, R. K., \& Francesco, A. M. (2003). Dispositional traits and turnover intention: Examining the mediating role of job satisfaction and affective commitment. International Journal of Manpower, 24(3), 284-298.

Conchar, M. P., Zinkhan, G. M., Peters, C., \& Olavarrieta, S. (2004). An integrated framework for the conceptualization of consumers' perceivedrisk processing. Journal of the Academy of Marketing Science, 32(4), 418-436.

Cooper, R. G. (1993). Winning at new products: Accelerating the process from idea to launch, (2nd ed.). Reading, MA: Addison-Wesley.

Cooper, R. G., \& de Brentani, U. (1984). Criteria for screening new industrial products. Industrial Marketing Management, 13(3), 149-156.

Cooper, R. G., Edgett, S. J., \& Kleinschmidt, E. J. (1997). Portfolio management in new product development: Lessons from the leaders - I. Research Technology Management, 40(5), 16-28.

Cooper, R. G., Edgett, S. J., \& Kleinschmidt, E. J. (1997). Portfolio management in new product development: Lessons from the leaders - II. Research Technology Management, 40(6), 43-52.

Cooper, R. G., Edgett, S. J., \& Kleinschmidt, E. J. (1999). New product portfolio management: Practices and performance. Journal of Product Innovation Management, 16, 333-351.

Cooper, R. G., Edgett, S. J., \& Kleinschmidt, E. J. (2001). Portfolio management for new product development: Results of an industry practices study. $R \& D$ Management, 31, 361-380. 
Cooper, R. G., Edgett, S. J., \& Kleinschmidt, E. J. (2001). Portfolio management for new products, (2nd ed.). Cambridge, MA: Perseus Publishing.

Cooper, R. G., Edgett, S. J., \& Kleinschmidt, E. J. (2004). Benchmarking best NPD practices - I. Research Technology Management, 47(1), 31-43.

Cooper, R. G., Edgett, S. J., \& Kleinschmidt, E. J. (2004). Benchmarking best NPD practices - II. Research Technology Management, 47(3), $50-59$.

Crawford, C. M. (1980). Defining the charter for product innovation. Sloan Management Review, 22(1), 3-12.

Crawford, C. M. (1986). Evaluating new products: A system, not an act. Business Horizons, 29(6), 48-55.

DeYoung, C. G. (2006). Higher-order factors of the big five in a multiinformant sample. Journal of Personality and Social Psychology, 91(6), $1138-1151$

Eagly, A. H., \& Johnson, B. T. (1990). Gender and leadership style: A metaanalysis. Psychological Bulletin, 108(2), 233-256.

Eisenhardt, K. M. (1989). Building theories from case study research. Academy of Management Review, 14(4), 532-550.

Goldberg, L. R. (1990). An alternative "description of personality": The big-five factor structure. Journal of Personality and Social Psychology, 59(6), $1216-1229$.

Griffin, A. (1997). PDMA research on new product development practices: Updating trends and benchmarking practices. Journal of Product Innovation Management, 14, 429-458.

Gupta, A. K., \& Govindarajan, V. (1984). Business unit strategy, managerial characteristics, and business unit effectiveness at strategy implementation. Academy of Management Journal, 27(1), 25-41.

Hart, S., Hultink, E. J., Tzokas, N., \& Commandeur, H. R. (2003). Industrial companies' evaluation criteria in new product development gates. Journal of Product Innovation Management, 20(1), 22-36.

Henard, D. H., \& Szymanski, D. M. (2001). Why some new products are more successful than others. Journal of Marketing Research, 38(3), 363-375.

Hoeffler, S. (2003). Measuring preferences for really new products. Journal of Marketing Research, 40(4), 406-420.

Hofer (1980). Turnaround strategies. Journal of Business Strategy, 1(1), $19-31$.

Hoffman, R. C., \& Hegarty, W. H. (1993). Top management influence on innovations: Effects of executive characteristics and social culture. Journal of Management, 19(3), 549-574.

Judge, T. A., Erez, A., Thoresen, C. J., \& Bono, J. E. (2002). Are measures of self-esteem, neuroticism, locus of control, and generalized self-efficacy indicators of a common core construct? Journal of Personality and Social Psychology, 83(3), 693-710.

Judge, T. A., Locke, E. A., \& Durham, C. C. (1997). The dispositional causes of job satisfaction: A core evaluations approach. Research in Organizational Behavior, 19, 151-188.

Judge, T. A., Thoresen, C. J., Pucik, V., \& Welbourne, T. M. (1999). Managerial coping with organizational change: A dispositional perspective. Journal of Applied Psychology, 84(1), 107-122.

Kleinschmidt, E. J., \& Cooper, R. G. (1995). The relative importance of new product success determinants - Perception versus reality. $R \& D$ Management, 25(3), 281-298.

Lewin, A. Y., \& Weber, W. L. (1969). Management game teams in education and organization research: An experiment on risk taking. Academy of Management Journal, 12(1), 49-58.

Lucas, G. H., \& Bush, A. J. (1988). The marketing-R\&D interface: Do personality factors have an impact? Journal of Product Innovation Management, 5(4), 257-268.

Mayer, J. D. (1995). The system-topics framework and the structural arrangement of systems within and around personality. Journal of Personality, 63(3), 459-493.

Mayer, J. D. (1998). A systems framework for the field of personality psychology. Psychological Inquiry, 9, 118-144.

Mayer, J. D. (2003). Structural divisions of personality and the classification of traits. Review of General Psychology, 7, 381-401.

McCracken, G. (1988). The long interview. Newbury Park, CA: Sage Publications.
McDonough, E. F., III, \& Spital, F. C. (2003). Managing project portfolios. Research Technology Management, 46(3), 40-46.

Miles, M. B., \& Huberman, A. M. (1994). Qualitative data analysis. Thousand Oaks, CA: Sage Publications.

Milliken, F. J., \& Lant, T. K. (1991). The impact of organizations recent performance history on strategic persistence and change: The role of managerial interpretations. In J. Dutton, A. Huff, \& P. Shrivastava (Eds.), Advances in strategic management, Vol. 7 (pp. 129-156). Greenwich, CT: JAI Press.

Montoya-Weiss, M., \& Calantone, R. J. (1994). Determinants of new product performance: A review and meta-analysis. Journal of Product Innovation Management, 11(5), 397-417.

Mullins, J. W., Forlani, D., \& Walker, O. C., Jr. (1999). Effects of organizational and decision-maker factors on new product risk taking. Journal of Product Innovation Management, 16(3), 282-294.

Nunnally, J. C. (1978). Psychometric theory, (2nd ed.). New York, NY: McGraw-Hill.

Oreg, S. (2003). Resistance to change: Developing an individual differences measure. Journal of Applied Psychology, 88(4), 680-693.

Poolton, J., \& Barclay, I. (1998). New product development from past research to future applications. Industrial Marketing Management, 27(3), 197-212.

Renn, R. W., Allen, D. G., Fedor, D. B., \& Davis, W. D. (2005). The roles of personality and self-defeating behaviors in self-management failure. Journal of Management, 31(5), 659-679.

Rochford, L. (1991). Generating and screening new product ideas. Industrial Marketing Management, 20(4), 287-296.

Ronkainen, I. A. (1985). Criteria changes across product development stages. Industrial Marketing Management, 14(3), 171-178.

Sherman, R. (1974). The psychological difference between ambiguity and risk. The Quarterly Journal of Economics, 88, 166-169.

Singh, J. V. (1986). Performance, slack, and risk taking in organizational decision making. Academy of Management Journal, 29(3), 562-585.

Sitkin, S. B., \& Weingart, L. R. (1995). Determinants of risky decision-making behavior: A test of the mediating role of risk perceptions and propensity. Academy of Management Journal, 38(6), 1573-1592.

Srivastava, R. K., Shervani, T. A., \& Fahey, L. (1999). Marketing, business processes, and shareholder value: An organizationally embedded view of marketing activities and the discipline of marketing. Journal of Marketing, 63, 168-179 (Special Issue).

Stake, R. (1995). The art of case study research. Thousand Oaks, CA: Sage Publications.

Szilagyi, A. D., \& Schweiger, D. M. (1984). Matching managers to strategies: A review and suggested framework. Academy of Management Review, 9(4), 626-637.

Thoresen, C. J., Bradley, J. C., Bliese, P. D., \& Thoresen, J. D. (2004). The big five personality traits and individual job performance growth trajectories in maintenance and transitional job stages. Journal of Applied Psychology, $89(5), 835-853$.

Tzokas, N., Hultink, E. J., \& Hart, S. (2004). Navigating the new product development process. Industrial Marketing Management, 33(7), 619-626.

van Bruggen, G. H., Smidts, A., \& Wierenga, B. (1998). Improving decision making by means of a marketing decision support system. Management Science, 44(5), 645-658.

Wheelwright, S. C., \& Clark, K. B. (1992). Revolutionizing product development. New York: The Free Press.

Yin, R. K. (1994). Case study research. Thousand Oaks, CA: Sage Publications.

Regina C. McNally is an assistant professor of marketing in The Eli Broad College of Business at Michigan State University. Her research interests focus on the processes and outcomes of business-to-business marketing decisions, particularly in the areas of new product development, governance structures, and customer relationship management. She has published in multiple journals, including the Journal of the Academy of Marketing Science and the Journal of Business-to-Business Marketing, and has articles forthcoming in the Journal of Product Innovation Management and R\&D Management. 
Serdar S. Durmusoglu is an assistant professor of marketing at the School of Business Administration at the University of Dayton. He earned his Ph.D. in Marketing from Michigan State University. $\mathrm{He}$ also holds an MBA from Purdue University in West Lafayette, Indiana and a Bachelor's degree in Mathematics from Boĝaziçi University in Istanbul, Turkey. In addition, he has several years of corporate work experience. Dr. Durmuşoĝlu's research interests are in the areas of new product design and development, innovation, and information technology. He has published in the Journal of Product Innovation Management, R\&D Management, and the Journal of Product and Brand Management among others.

Roger J. Calantone is the Eli Broad University Professor of Business at Michigan State University. He is also the director of the Center for Entrepreneurial Strategy, and adjunct professor of economics. His principal research work is in the areas of new product development, dynamic systems, and decisions support. $\mathrm{He}$ has published articles in the Journal of Marketing, Journal of Marketing Research, Marketing Science, Industrial Marketing Management, among others.
Nukhet Harmancioglu is an Assistant Professor of Marketing. She has completed her doctoral work in marketing and international business at the Marketing and Supply Chain Management department, Michigan State University. Nukhet earned her MBA with honors from the Bosphorus University and has also earned degrees from the Middle East Technical University and the Izmir American Collegiate Institute. She is the 2005 winner of the Product Development Management Association Dissertation Proposal Competition and 2006 Academy of Marketing Science Jane Fenyo Award. Her research interests span the fields of strategic marketing management, new product development, and international business. She has published in various conference proceedings and has forthcoming publications in the Journal of Product and Innovation Management, Journal of International Business Studies and R\&D Management. 